\title{
Investigation of oxidative stress-related candidate genes as risk factors for drug-induced liver injury due to co-amoxiclav
}

\author{
Mohammad A. Alshabeeb ${ }^{1,2,3}$, Guruprasad P. Aithal ${ }^{4,5}$, Ann K. Daly ${ }^{1}$ \\ ${ }^{1}$ Translational and Clinical Research Institute, Faculty of Medical Sciences, \\ Newcastle University, Newcastle upon Tyne, United Kingdom, ${ }^{2}$ Developmental \\ Medicine Department, King Abdullah International Medical Research Center \\ (KAIMRC), ${ }^{3}$ King Saud Bin Abdulaziz University for Health Sciences, Riyadh, \\ Saudi Arabia, ${ }^{4}$ NIHR Nottingham Biomedical Research Centre at the Nottingham \\ University Hospitals NHS Trust and the University Of Nottingham, ${ }^{5}$ Nottingham \\ Digestive Diseases Centre, School of Medicine, University Of Nottingham, \\ Nottingham, UK.
}




\begin{abstract}
The liver is susceptible to drug toxicity due to its vital role in xenobiotic metabolism and elimination. In addition to human leukocyte antigen (HLA) variants, which were previously determined as risk factors for drug-induced liver injury (DILI) due to coamoxiclav, other non-HLA genes may contribute to hepatotoxicity risk. In this study, the association between DILI due to co-amoxiclav and several non-HLA genes was investigated. Association of variants in candidate genes (SOD2, GPX1, GSTM1, and GSTT1) with DILI due to various drugs was reported previously in other DILI cohorts. This study examined relevance in a co-amoxiclav-DILI cohort. One hundred and sixty five co-amoxiclav DILI cases were recruited from several European countries by two different studies (DILIGEN and iDILIC). A North-East England population group $(n=334)$ was used as the control group. PCR assays were used to genotype for the GSTM1 and GSTT1 null alleles with TaqMan SNP genotyping assays used for SOD2 (rs4880) and GPX1 (rs1050450). Fisher's exact test was used to assess differences in significance between cases and controls. None of the studied variants (SOD2 rs4880, GPX1 rs 1050450, GSTM1 null allele, and GSTT1 null allele) was significantly associated with co-amoxiclav DILI compared with the control group. No significant differences between cases and controls were seen when combined SOD2/GPX1 genotypes and GST genotypes were considered. Despite the possible functional relevance and the previously reported contribution of the selected genes to DILI, our study failed to confirm associations between the selected genes and liver injury induced by co-amoxiclav.
\end{abstract}

Keywords: oxidative stress genes, SOD2, GPX1, GSTM1, GSTT1, drug-induced liver injury (DILI), 


\section{Introduction}

Antimicrobials are the leading hepatotoxic drug group and are responsible for up to $70 \%$ of all documented DILI cases (Hussaini and Farrington, 2007). Co-amoxiclav was reported among the top antimicrobials causing DILI and was the most common beta-lactam associated with DILI development in a study conducted in Spain involving 505 different drugs (Andrade et al., 2005), and in the USA Drug Induced Liver Injury Network (DILIN) study (Fontana et al., 2009).

Several HLA loci; DQB1*06, DRB1*15:01 (DRB1*15:02 in Asians), A*02:01 and B*18:01, were identified as genetic determinants of co-amoxiclav-induced hepatotoxicity (Andrade et al., 2004, Donaldson et al., 2010, Lucena et al., 2011, Kaliyaperumal et al., 2018). In the UK-wide DILIGEN study (Donaldson et al., 2010), the DRB1*15 allele was found to be a risk factor in co-amoxiclav cases, supporting findings from two earlier smaller studies (Hautekeete et al., 1999, O'Donohue et al., 2000) ( $\mathrm{n}=35$ and 22, respectively).

There are some previous reports of genes relevant to oxidative stress contributing to DILI risk since oxidative stress within the liver may be important in the development of idiosyncratic DILI (Lucena et al., 2008, Li et al., 2013). These include superoxide dismutase 2 (SOD2) and glutathione peroxidase 1 (GPX1) which have a direct role in detoxicating reactive oxygen species (ROS) together with the GST enzymes GSTM1 and T1 which may detoxicate compounds such as malondialdehyde and 4hydroxynonenal which are produced when ROS causes lipid peroxidation. The rs4880 SOD2 SNP is a nonsynonymous SNP which was reported to be a contributing risk factor $(\mathrm{P}=0.037)$ to hepatocellular DILI induced by various drugs including antituberculosis (TB) agents in 115 Taiwanese patients (Huang et al., 2007). On the contrary, findings obtained by Lucena et al. (2010) showed a significant association of the $\mathrm{T}$ variant with cholestatic/mixed trait in a study involving 185 DILI Spanish patients $(\mathrm{Pc}=0.0058)$. GPX1 ( $\mathrm{rs} 1050450)$ was also reported to be associated with drug-induced cholestatic hepatotoxicity in this study. Individuals who carried GSTM1/GSTT1-double null genotype were reported to be at increased risk of DILI due to exposure to a number of different medications including troglitazone and coamoxiclav (Lucena et al., 2008; Watanabe et al., 2003). The aim of the current study was to replicate the association reported previously between both GST genes, SOD2 
and GPX1 and co-amoxiclav-related DILI through genotyping a larger number of coamoxiclav cases.

\section{Methods}

DILI cases

Cases of co-amoxiclav DILI $(\mathrm{n}=165)$ were collected retrospectively and prospectively from collaborators in several European countries (Netherlands (1 case), Iceland (10 cases), Sweden (5 cases)) but mainly from centres throughout the United Kingdom (149 cases) based on criteria for DILI detailed below. Participants were recruited via the DILIGEN and iDILIC studies and have been described in more detail previously (Donaldson et al. (2000), Lucena et al. (2011) and Cirulli et al. (2019)). All cases were of white European ethnicity. Clinical and biochemical data are described in Table 1. Ethical approval for the UK study was obtained from the Leeds East Research Ethics committee (ref 04/Q1206/9). The other centres obtained ethical approval from the relevant local ethics committees.

\section{Inclusion criteria and patients eligibility}

To confirm hepatotoxicity, patients had to fulfil at least one of three diagnostic criteria: 1) alanine aminotransferase (ALT) $>5 \mathrm{x}$ the upper normal limit (ULN), 2) $\mathrm{ALT} \geq 3 \mathrm{x}$ ULN plus bilirubin $\geq 2 \mathrm{x}$ ULN, or 3 ) alkaline phosphatase (ALP) $>2 \mathrm{x}$ ULN. The patients who met the above criteria were also required to be over 18 years of age, able to give informed consent and their hepatotoxicity suspected to be due to co-amoxiclav. Confirmation that the cases appeared likely to represent DILI induced by co-amoxiclav was made by expert adjudicating hepatologists (Professor Guruprasad Aithal, Nottingham University and Professor Einar Bjornsson, Reykjavik, University of Iceland) using international consensus criteria (RUCAM scoring) (Benichou, 1990, Aithal et al., 2011).

\section{DNA preparation from DILI cases}

DNA was prepared from $5 \mathrm{ml}$ blood samples anticoagulated with EDTA using a perchlorate-chloroform extraction method as described previously (Daly et al., 1996). 


\section{Control samples}

Up to 334 apparently healthy individuals recruited from North-East England were used as a community control group and genotyped directly. Details of this group including DNA preparation method have been described previously (Velaga et al., 2004). Compliance of the control group with standard quality criteria was tested using Hardy-Weinberg equilibrium. Cases and controls were not matched for age, sex, or BMI. Drug histories on the population controls were not available. However, for rare adverse drug reactions such as co-amoxiclav DILI affecting less than $1 \%$ of the poulation, it is possible to use population controls without clinical matching and retain adequate statistical power to detect significant effects (Nelson et al., 2009).

SOD2 and GPXI assays

TaqMan SNP genotyping assays were used to genotype the cases for SOD2 and GPX1 polymorphisms. A readymade assay (reference number: C__8709053_10, catalog number: 4351379) designed by Applied Biosystems was used to genotype SOD2 (rs4880) while a custom TaqMan assay was used for GPX1 (rs1050450). The primers used and DNA cycling conditions were similar to those used by Gao et al. (2017). Allelic discrimination analysis was performed using a Step-One Real-Time PCR machine. A small number of cases failed genotyping.

\section{GSTM1 and GSTT1 assays}

The primers used to amplify GSTM1 (219 base pairs (bp)) and GSTT1 (459 bp) genes were previously described by Xiong et al. (2001). The primers used for the positive internal control (TNF- $\alpha, 340 \mathrm{bp}$ ) were obtained from Parnes et al. (2010). PCR cycling conditions used for both assays were similar to the conditions used by Xiong et al. (2001). The primers of internal positive control were added to each assay to confirm successful PCR amplification. The PCR products were visualized on $2 \%$ agarose gel stained with ethidium bromide. The absence of GSTM1 or GSTT1 fragment indicates the null genotype. However, absence of the TNF- $\alpha$ DNA band showed that the PCR amplification was unsuccessful and the experiment must be repeated.

\section{Statistical analysis}

Graphpad PRISM version 5.0 was used to calculate P-values, odds ratios and 95\% confidence intervals. Compliance with Hardy-Weinberg equilibrium was also 
determined using a web-based calculator available at http://www.oege.org/software/hardy-weinberg.shtml.

\section{Results}

SOD2 and GPX1 genotyping

As summarized in Table 2, genotyping results for SOD2 (rs4880, C/T) and GPX1 (rs1050450, C/T) showed no significant difference in genotype distributions between co-amoxiclav cases and community controls $(\mathrm{OR}=1.02,95 \% \mathrm{CI}=0.7-1.6 ; \mathrm{P}=1.0$ for $\mathrm{SOD} 2$ variant carriage and $\mathrm{OR}=1.26,95 \% \mathrm{CI}=0.9-1.9 ; \mathrm{P}=0.25$ for $\mathrm{GPX} 1$ ). When cases with a mixed and cholestatic phenotypes only were considered $(n=133)$, no significant differences were seen between these cases and the control group for either genotype $(\mathrm{P}=0.64$ and 0.15 for the carriage of SOD2 and GPX1 variants alleles, respectively). Since causality of the DILI reaction for 21 of the cases was assessed as only possibly related to co-amoxiclav, we also assessed the group showing probable causality (RUCAM of 6 or higher) separately but did not see any significant differences between cases and controls for either SOD2 or GPX1 (Table 2).

The possibility that concurrent carriage of both variant alleles might be a risk factor was also considered. In the cohort as a whole, we found that $37.6 \%$ of cases were positive for both variants compared with $36.7 \%$ of controls but this difference was not significant $(\mathrm{P}=0.11)$ (Table 3$)$. We also saw no significance $(\mathrm{P}=0.17)$ when cholestatic and mixed cases only were considered (Table 3 ). These findings indicate no role for these SOD2 or GPX1 polymorphisms in DILI development due to coamoxiclav.

\section{GST null genotypes}

The frequency of null genotypes related to GSTM1 and GSTT1 genes did not show significant differences in DILI cases compared to controls (Table 4a) except that a trend towards a protective effect with the GSTM1 null genotype was seen $(\mathrm{OR}=0.7$, $95 \% \mathrm{CI}=0.5-1.0 ; \mathrm{P}=0.08$ ). Subgroup analysis of the case phenotypes showed no association for cholestatic or mixed phenotypes only with either variant $(\mathrm{P}=0.21$ for both) or for cases showing RUCAM $>6(\mathrm{P}=0.16$ and $\mathrm{P}=0.9)$. When combined GST deletion genotypes were investigated (Table 4b), no significantly altered risk was 
seen in cases where one or both genes were deleted for the entire cohort $(\mathrm{P}=0.20)$ or cholestatic/mixed cases only $(\mathrm{P}=0.46)$.

Comparison of data from current study with previous reports on DILI due to coamoxiclav

As shown in Table 5, we compared our findings for genotypes in co-amoxiclav DILI with those reported previously for a smaller cohort from Spain (Lucena et al, 2008 and 2010). This comparison shows very similar findings by Lucena et al. (2010) to those reported here for SOD2 and GPXI genotypes. It was not possible to compare single GST genotypes directly as the earlier study did not provide these for coamoxiclav alone but we compared combined GSTM1 and T1 genotypes. Though the findings look broadly similar, the current study saw no trend towards significance for the combined GST null genotype reported previously (Lucena et al. 2008).

\section{Discussion}

Four candidate genes with previously reported associations with DILI development due to their putative role in reducing oxidative stress were selected for study (Lucena, et al., 2010). Despite the available evidence of a possible contribution of the oxidative stress genes particularly SOD2 and GPX1 in DILI susceptibility (Huang et al., 2007, Lucena et al., 2010), our genotyping experiments which involved these genes failed to show similar findings in our DILI cohort which was larger than those used in the earlier studies. The DILI association reported by Huang et al. (2007) was limited to anti-TB drugs in Taiwanese population. It is important to realize that significant ethnic variability in genotype frequency for the SOD2 SNP between Taiwanese and European controls used was noted (Lucena et al., 2010). Such a difference may possibly affect the overall analysis of gene-disease association among populations of different ancestries. The positive findings of Lucena et al. (2010), on the other hand, were related to DILI due to multiple drugs but did involve 37 coamoxiclav cases. Similar to our findings, these cases which were the largest DILI group among the samples studied by Lucena et al. (2010) did not show significant SOD2 or GPX1 genotype distribution differences when co-amoxiclav cases only $(n=37)$ were compared with a drug-matched control group. This was also found for cases due to co-amoxiclav with cholestatic/mixed phenotypes, both in the Lucena et 
al (2010) study $(n=25)$ and in the current one $(n=133)$. The most significant findings reported by Lucena et al. (2010) relate to combined genotypes for SOD2/GPX1 and cholestatic/mixed DILI. The current study has larger numbers of cholestatic/mixed DILI cases with co-amoxiclav alone but was unable to confirm these findings. Lucena et al. (2010) suggested that the association they observed is more important for drugs that cause toxicity by targeting mitochondria but this is unlikely to be an important target in DILI due to co-amoxiclav. However, the fact that Urban et al. (2012) failed to find any evidence that SOD2 and GPX1 were important in a larger number $(\mathrm{n}=783)$ of cholestatic/mixed DILI due to a wide range of drugs also should be considered. It remains possible that the Lucena et al. (2010) findings represent an artefact due to small numbers of cases, especially since to see any significance it was necessary for them to do subgroup analysis.

Our investigation of the possible role of null genotypes of the glutathione Stransferases GSTM1 and GSTT1 on DILI development due to co-amoxiclav also showed lack of contribution to drug hepatotoxicity. The frequency of combined, single or no GSTM1/T1 deletions did not show significant differences between cases and control group. GSTM1 null genotype, but not GSTT1, was previously reported as a risk factor for developing DILI in a number of Asian studies involving Indian, Taiwanese and Chinese population. One Asian study which investigated DILI due to troglitazone did report that a combined null genotype for GSTM1 and T1 was a risk factor for serious DILI (Watanabe et al., 2003). In one Spanish study, those with a deletion of GSTM1 showed a lower risk of drug hepatotoxicity (Lucena et al., 2008) whereas the GSTT1 deletion (but not the GSTM1) was more common in anti-TB DILI cases of another Spanish cohort than in matched controls (Leiro et al., 2008). In agreement with the Watanabe et al. (2003) findings, Lucena et al. (2008) found that carriage of double mutation (GSTM1-/GSTT1-) increased the risk for DILI development due to use of multiple drugs by 2.7 fold whereas a weaker association was seen in co-amoxiclav cases only. The inconsistency noticed between our results and the findings seen in the previous studies may refer to the fact that most of those studies used multiple drug DILI cases rather than stratifying the cases according to the possible causative drugs. Secondly, the majority of positive associations reported between GST genes and DILI were more specific to anti-TB drugs and NSAIDs. Thirdly, the studies conducted mainly involved Asian populations where GST 
genotype frequency differs significantly to European populations (Leiro et al., 2008). The increased risk of developing hepatic injury shown in co-amoxiclav cases only with combined gene deletions reported by Lucena and colleagues (2008) may possibly have been a chance observation as a result of the limited number of cases used $(n=32)$. This conclusion is supported by our findings which involved much larger numbers of co-amoxiclav cases $(n=162)$ and showed no significant association with null genotypes of both GST genes. The large study by Urban et al. (2012) which includes cases of DILI due to a large number of different drugs also failed to detect any signals involving GST genes, either when GWAS was performed or when smaller number of metabolism-related genes including the GSTs were studied.

In conclusion, although the candidate genes studied here are biologically plausible causes of DILI, show high expression in the liver and previous associations with liver toxicity, none of them were found to be an important risk factor for DILI in patients treated by co-amoxiclav.

\section{Acknowledgements}

Collection of the DILI cases was supported by the UK Department of Health and the International Serious Adverse Events Consortium. We are grateful to Munir Pirmohamed, John Dillon, Einar Bjornsson, Mia Wadelius, Par Hallberg and AnkeHilse Maitland-van der Zee for coordinating patient recruitment and adjudication. Special thanks to the late Pete Donaldson for access to the control DNA. 


\section{References}

Aithal GP, Watkins PB, Andrade RJ, Larrey D, Molokhia M, Takikawa H, Hunt CM, Wilke RA, Avigan M, Kaplowitz N, Bjornsson E, Daly AK (2011) Case definition and phenotype standardization in drug-induced liver injury. Clinical pharmacology and therapeutics 89:806-15.

Andrade RJ, Lucena MI, Alonso A, Garcia-Cortes M, Garcia-Ruiz E, Benitez R, Fernandez MC, Pelaez G, Romero M, Corpas R, Duran JA, Jimenez M, Rodrigo L, Nogueras F, Martin-Vivaldi R, Navarro JM, Salmeron J, De La Cuesta FS, Hidalgo R (2004) HLA class II genotype influences the type of liver injury in drug-induced idiosyncratic liver disease. Hepatology 39:160312.

Andrade RJ, Lucena MI, Fernandez MC, Pelaez G, Pachkoria K, Garcia-Ruiz E, Garcia-Munoz B, Gonzalez-Grande R, Pizarro A, Duran JA, Jimenez M, Rodrigo L, Romero-Gomez M, Navarro JM, Planas R, Costa J, Borras A, Soler A, Salmeron J, Martin-Vivaldi R, Spanish Group for the Study of DrugInduced Liver D (2005) Drug-induced liver injury: an analysis of 461 incidences submitted to the Spanish registry over a 10-year period. Gastroenterology 129:512-21.

Benichou C (1990) Criteria of drug-induced liver disorders. Report of an international consensus meeting. J Hepatol 11:272-6.

Donaldson P, Daly AK, Henderson J, Graham J, Pirmohamed M, Bernal W, Day CP, Aithal GP (2010) Human leucocyte antigen class II genotype in susceptibility and resistance to co-amoxiclav-induced liver injury. J Hepatol 53:1049-53.

Fontana RJ, Watkins PB, Bonkovsky HL, Chalasani N, Davern T, Serrano J, Rochon J, Group DS (2009) Drug-Induced Liver Injury Network (DILIN) prospective study: rationale, design and conduct. Drug Saf 32:55-68.

Gao H, Liu C, Song S, Zhang C, Ma Q, Li X, Xu L (2017) GPX1 Pro198Leu polymorphism and GSTP1 Ile105Val polymorphisms are not associated with the risk of schizophrenia in the Chinese Han population. Neuroreport 28:969972.

Hautekeete ML, Horsmans Y, Van Waeyenberge C, Demanet C, Henrion J, Verbist L, Brenard R, Sempoux C, Michielsen PP, Yap PS, Rahier J, Geubel AP (1999) HLA association of amoxicillin-clavulanate--induced hepatitis. Gastroenterology 117:1181-6.

Huang YS, Su WJ, Huang YH, Chen CY, Chang FY, Lin HC, Lee SD (2007) Genetic polymorphisms of manganese superoxide dismutase, $\mathrm{NAD}(\mathrm{P}) \mathrm{H}$ :quinone oxidoreductase, glutathione S-transferase M1 and T1, and the susceptibility to drug-induced liver injury. J Hepatol 47:128-34.

Hussaini SH, Farrington EA (2007) Idiosyncratic drug-induced liver injury: an overview. Expert opinion on drug safety 6:673-84.

Kaliyaperumal K, Grove JI, Delahay RM, Griffiths WJ, Duckworth A, Aithal GP (2018) Pharmacogenomics of drug-induced liver injury (DILI): molecular biology to clinical applications. Journal of hepatology 69:948-957.

Leiro V, Fernandez-Villar A, Valverde D, Constenla L, Vazquez R, Pineiro L, Gonzalez-Quintela A (2008) Influence of glutathione S-transferase M1 and T1 homozygous null mutations on the risk of antituberculosis drug-induced hepatotoxicity in a Caucasian population. Liver international : official journal of the International Association for the Study of the Liver 28:835-9. 
Li C, Long J, Hu X, Zhou Y (2013) GSTM1 and GSTT1 genetic polymorphisms and risk of anti-tuberculosis drug-induced hepatotoxicity: an updated metaanalysis. European journal of clinical microbiology \& infectious diseases 32:859-868.

Lucena MI, Andrade RJ, Martinez C, Ulzurrun E, Garcia-Martin E, Borraz Y, Fernandez MC, Romero-Gomez M, Castiella A, Planas R, Costa J, Anzola S, Agundez JA, Spanish Group for the Study of Drug-Induced Liver D (2008) Glutathione S-transferase $\mathrm{m} 1$ and $\mathrm{t} 1$ null genotypes increase susceptibility to idiosyncratic drug-induced liver injury. Hepatology 48:588-96.

Lucena MI, Garcia-Martin E, Andrade RJ, Martinez C, Stephens C, Ruiz JD, Ulzurrun E, Fernandez MC, Romero-Gomez M, Castiella A, Planas R, Duran JA, De Dios AM, Guarner C, Soriano G, Borraz Y, Agundez JA (2010) Mitochondrial superoxide dismutase and glutathione peroxidase in idiosyncratic drug-induced liver injury. Hepatology 52:303-12.

Lucena MI, Molokhia M, Shen Y, Urban TJ, Aithal GP, Andrade RJ, Day CP, RuizCabello F, Donaldson PT, Stephens C, Pirmohamed M, Romero-Gomez M, Navarro JM, Fontana RJ, Miller M, Groome M, Bondon-Guitton E, Conforti A, Stricker BH, Carvajal A, Ibanez L, Yue QY, Eichelbaum M, Floratos A, Pe'er I, Daly MJ, Goldstein DB, Dillon JF, Nelson MR, Watkins PB, Daly AK (2011) Susceptibility to Amoxicillin-Clavulanate-Induced Liver Injury Is Influenced by Multiple HLA Class I and II Alleles. Gastroenterology 141:338-47.

Nelson, M., Bacanu, S., Mosteller, M., Li, L., Bowman, C., Roses, A., et al. (2009). Genome-wide approaches to identify pharmacogenetic contributions to adverse drug reactions. Pharmacogenomics J 9, 23-33.

O'Donohue J, Oien KA, Donaldson P, Underhill J, Clare M, Macsween RN, Mills PR (2000) Co-amoxiclav jaundice: clinical and histological features and HLA class II association. Gut 47:717-20.

Parnes A, Nikiforow S, Berliner N, Vanasse GJ (2010) Single nucleotide polymorphisms in the human TNF gene are associated with anaemia and neutropenia in a cohort of patients with de novo myelodysplastic syndrome. British journal of haematology 150:700-1.

Urban TJ, Shen Y, Stolz A, Chalasani N, Fontana RJ, Rochon J, Ge D, Shianna KV, Daly AK, Lucena MI, Nelson MR, Molokhia M, Aithal GP, Floratos A, Pe'er I, Serrano J, Bonkovsky H, Davern TJ, Lee WM, Navarro VJ, Talwalkar JA, Goldstein DB, Watkins PB, Drug-Induced Liver Injury N, Diligen, Eudragene, Spanish DR, International Serious Adverse Events C (2012) Limited contribution of common genetic variants to risk for liver injury due to a variety of drugs. Pharmacogenetics and genomics 22:784-95.

Velaga MR, Wilson V, Jennings CE, Owen CJ, Herington S, Donaldson PT, Ball SG, James RA, Quinton R, Perros P, Pearce SH (2004) The codon 620 tryptophan allele of the lymphoid tyrosine phosphatase (LYP) gene is a major determinant of Graves' disease. The Journal of clinical endocrinology and metabolism 89:5862-5.

Watanabe I, Tomita A, Shimizu M, Sugawara M, Yasumo H, Koishi R, Takahashi T, Miyoshi K, Nakamura K, Izumi T, Matsushita Y, Furukawa H, Haruyama H, Koga T (2003) A study to survey susceptible genetic factors responsible for troglitazone-associated hepatotoxicity in Japanese patients with type 2 diabetes mellitus. Clinical pharmacology and therapeutics 73:435-55. 
Xiong P, Bondy ML, Li D, Shen H, Wang LE, Singletary SE, Spitz MR, Wei Q (2001) Sensitivity to benzo(a)pyrene diol-epoxide associated with risk of breast cancer in young women and modulation by glutathione S-transferase polymorphisms: a case-control study. Cancer research 61:8465-9. 
Table 1: Clinical and biochemical variables in co-amoxiclav cases $(n=165)$

\begin{tabular}{|c|c|}
\hline $\operatorname{Sex}(\mathrm{F} / \mathrm{M})$ & $79(47.9) / 86(52.1)$ \\
\hline Age at onset (years) & $63.1 \pm 12.8$ \\
\hline Time to onset (days) & $19.9 \pm 19.6$ \\
\hline Total days on drug & $9.2 \pm 10.4$ \\
\hline \multicolumn{2}{|l|}{$\underline{\text { Pattern of liver injury }}$} \\
\hline Cholestatic & $108(65.4)$ \\
\hline Hepatocellular & $27(16.4)$ \\
\hline Mixed & $30(18.2)$ \\
\hline \multicolumn{2}{|l|}{$\underline{\text { RUCAM scoring }}$} \\
\hline 3-5 (possible) & $21(12.7)$ \\
\hline 6-8 (probable) & $71(43.0)$ \\
\hline$>8$ (highly probable) & $73(44.3)$ \\
\hline Peak Bilirubin $(\mu \mathrm{mol} / \mathrm{l})$ & $221.4 \pm 161.8$ \\
\hline Peak ALT (U/1) & $420.4 \pm 422.7$ \\
\hline Peak ALP (U/1) & $516.8 \pm 393.4$ \\
\hline \multicolumn{2}{|l|}{$\underline{\text { Severity of DILI }}$} \\
\hline Mild & $15(9.1)$ \\
\hline Moderate & $145(87.9)$ \\
\hline Severe & $2(1.2)$ \\
\hline Very severe & $3(1.8)$ \\
\hline Cases with jaundice & $150(90.9)$ \\
\hline $\begin{array}{l}\text { Time taken for ALT/ALP to decrease to } \geq \\
50 \% \text { after discontinuation (days) }\end{array}$ & $44.4 \pm 42.3$ \\
\hline
\end{tabular}

- Percentages are shown in parentheses 
Table 2: SOD2 (rs4880) and GPX1 (rs1050450) genotyping results of cases versus controls

\begin{tabular}{|c|c|c|c|c|c|c|}
\hline & Current study & TT (\%) & CT (\%) & CC (\%) & $\begin{array}{c}\mathrm{P}- \\
\text { value }\end{array}$ & $\begin{array}{c}\mathrm{OR} \\
(95 \% \mathrm{CI})\end{array}$ \\
\hline \multirow{4}{*}{ SOD2 (rs4880) } & Cases $(n=158)$ & $\begin{array}{c}40 \\
(25.8)\end{array}$ & $\begin{array}{c}77 \\
(50.3)\end{array}$ & $41(23.9)$ & 1.0 & $\begin{array}{c}1.02 \\
(0.7-1.6)\end{array}$ \\
\hline & $\begin{array}{l}\text { Cholestatic and mixed cases } \\
\qquad(\mathrm{n}=133)\end{array}$ & $\begin{array}{c}29 \\
(21.8)\end{array}$ & $\begin{array}{c}66 \\
(49.6)\end{array}$ & $\begin{array}{c}38 \\
(28.6)\end{array}$ & 0.64 & $\begin{array}{c}0.89 \\
(0.6-1.4)\end{array}$ \\
\hline & $\begin{array}{c}\text { Cases with causality score } \geq 6 \\
(\mathrm{n}=138)\end{array}$ & $\begin{array}{c}38 \\
(27.5) \\
\end{array}$ & $\begin{array}{c}67 \\
(48.6) \\
\end{array}$ & $33(23.9)$ & 0.64 & $\begin{array}{c}1.14(0.7- \\
1.8)\end{array}$ \\
\hline & Controls $(n=331)$ & $\begin{array}{c}85 \\
(25.7)\end{array}$ & $159(48)$ & $87(26.3)$ & & \\
\hline \multirow{4}{*}{$\begin{array}{c}\text { GPX1 } \\
\text { (rs } 1050450)\end{array}$} & Cases $(n=157)$ & $14(8.9)$ & $\begin{array}{c}68 \\
(43.3) \\
(43.3)\end{array}$ & $75(47.8)$ & 0.25 & $\begin{array}{c}1.26 \\
(0.9-1.9)\end{array}$ \\
\hline & $\begin{array}{l}\text { Cholestatic and mixed cases } \\
\qquad(\mathrm{n}=133)\end{array}$ & $\begin{array}{c}14 \\
(10.5)\end{array}$ & $\begin{array}{c}58 \\
(43.6)\end{array}$ & $\begin{array}{c}61 \\
(45.9)\end{array}$ & 0.15 & $\begin{array}{c}1.36 \\
(0.9-2.0)\end{array}$ \\
\hline & $\begin{array}{c}\text { Cases with causality score } \geq 6 \\
\qquad(\mathrm{n}=136)\end{array}$ & $\begin{array}{c}10 \\
(7.3)\end{array}$ & $\begin{array}{c}57 \\
(41.9)\end{array}$ & $\begin{array}{c}68 \\
(50.0)\end{array}$ & 0.51 & $\begin{array}{c}1.14(0.8- \\
1.7)\end{array}$ \\
\hline & Controls $(n=334)$ & $18(5.4)$ & $137(41)$ & $\begin{array}{c}179 \\
(53.6)\end{array}$ & & \\
\hline
\end{tabular}

Percentages are shown in parentheses.

Odds ratios and $\mathrm{p}$ values are for carriage of the variant allele 
Table 3: Combined genotypes of SOD2 (rs4880) and GPX1 (rs1050450) of co-amoxiclav cases versus controls

\begin{tabular}{|c|c|c|c|c|c|}
\hline & $\begin{array}{l}\text { (A): positive for both } \\
\text { SNPs }\end{array}$ & $\begin{array}{l}\text { (B): positive for one of } \\
\text { the SNPs }\end{array}$ & $\begin{array}{l}\text { (C): negative for both } \\
\text { SNPs }\end{array}$ & $\begin{array}{l}\text { P-value } \\
\mathrm{A}+\mathrm{B} \text { vs } \mathrm{C}\end{array}$ & $\begin{array}{l}\text { OR } \\
(95 \% \mathrm{CI})\end{array}$ \\
\hline Co-amoxiclav cases $(n=157)$ & $59(37.6)$ & $83(52.9)$ & $15(9.5)$ & 0.11 & $1.73(0.93-3.21)$ \\
\hline $\begin{array}{l}\text { Cholestatic and mixed cases } \\
(n=133)\end{array}$ & $47(35.3)$ & $73(54.9)$ & $13(9.8)$ & 0.17 & $1.6(0.9-5.0)$ \\
\hline Controls $(n=300)$ & $110(36.7)$ & $145(48.3)$ & $45(15)$ & & \\
\hline
\end{tabular}


Table 4: GSTM1 and GSTT1 genotype distribution and number of GST positive genotypes among cases and controls

(a) Single genotypes

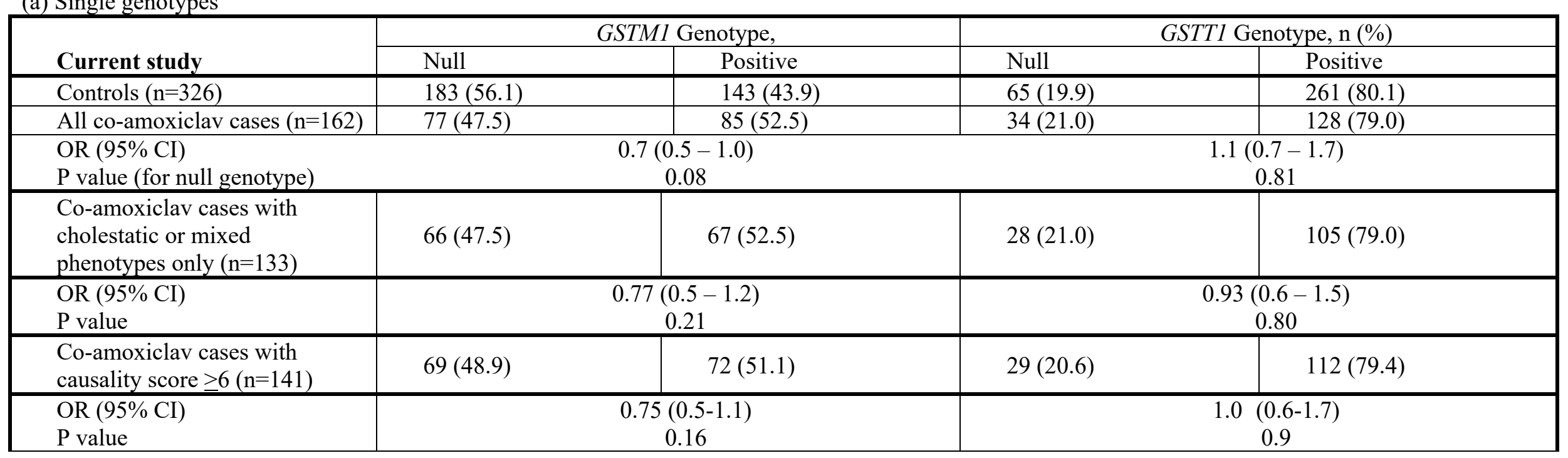

(b) Combined GST deletion genotypes

\begin{tabular}{|c|c|c|c|}
\hline & \multicolumn{3}{|c|}{ No. of Positive Genotypes, n (\%) } \\
\hline & Two & One & None \\
\hline Controls $(n=326)$ & $117(35.9)$ & $169(51.8)$ & $40(12.3)$ \\
\hline All cases $(n=162)$ & $68(42.0)$ & $76(46.9)$ & $18(11.1)$ \\
\hline $\mathrm{p}$ value & 0.20 & & \\
\hline Cholestatic and mixed only $(\mathrm{n}=137)$ & $53(39.8)$ & $65(48.9)$ & $15(11.3)$ \\
\hline $\mathrm{P}$ value & 0.46 & & \\
\hline
\end{tabular}

- $\quad p$ values were calculated comparing combined gene deletions in cases versus controls 
Table 5: Comparison of findings in the current study with those reported previously for co-amoxiclav DILI

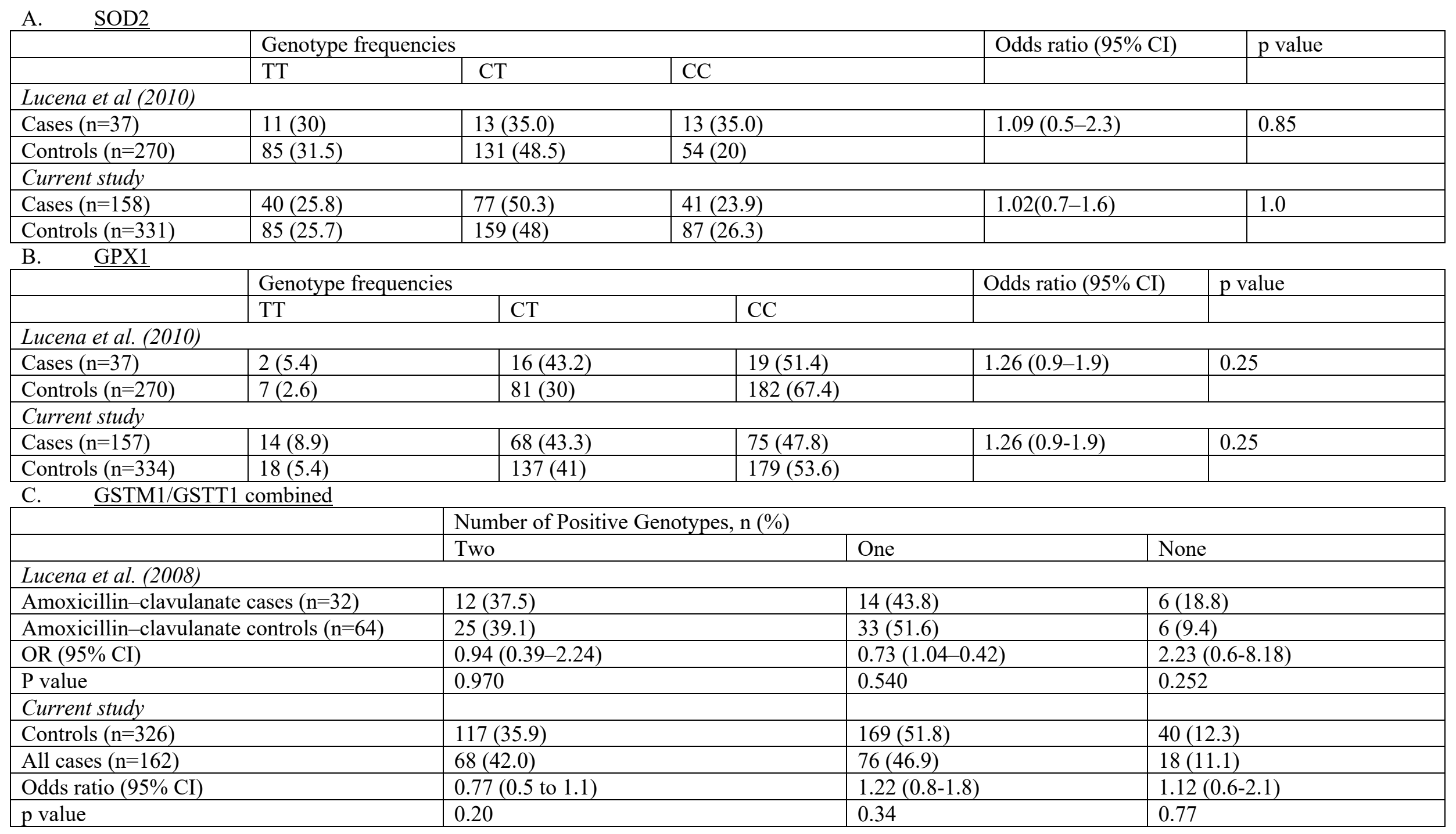

